\title{
6-gingerol alleviates inflammatory injury in DSS-induced ulcerative colitis mice by regulating NF-кB signaling
}

\author{
Yingyue Sheng ${ }^{1,2}$, Tielong $\mathrm{Wu}^{2}$, Yuanyuan Dai ${ }^{2}$, Linlin $\mathrm{Xu}^{2}$, Yao Zhong ${ }^{2}$, Yuzheng Xue ${ }^{2}$, Yaozhou Tian ${ }^{1}$ \\ ${ }^{1}$ Department of Gastroenterology, The Third Clinical Medical College of Nanjing University of Chinese Medicine, Nanjing, China; ${ }^{2}$ Department of \\ Gastroenterology, Affiliated Hospital of Jiangnan University, Wuxi, China \\ Contributions: (I) Conception and design: Y Sheng, T Wu ; (II) Administrative support: All authors ; (III) Provision of study materials or patients: All \\ authors; (IV) Collection and assembly of data: Y Sheng, Y Dai, L Xu, Y Zhong; (V) Data analysis and interpretation: All authors; (VI) Manuscript \\ writing: All authors; (VII) Final approval of manuscript: All authors. \\ Correspondence to: Yaozhou Tian. Department of Gastroenterology, The Third Clinical Medical College of Nanjing University of Chinese Medicine, \\ Nanjing 210000, China. Email: mini_rae@outlook.com; Yuzheng Xue. Department of Gastroenterology, Affiliated Hospital of Jiangnan University, \\ Wuxi 214000, China. Email: elfin_emu@163.com.
}

Background: The imbalance of Treg/Thl7 cells and inflammatory injury are believed to be involved in the development of ulcerative colitis (UC). Meanwhile, 6-gingerol has been reported to alleviate intestinal inflammatory damage in mice models, but the underlying mechanism remains elusive.

Methods: In this study, dextran sulfate sodium (DSS)-induced colitis mice models were established to examine the effects of 6-gingerol on IL-17 and IL-10 secretion, and the activation of NF- $\mathrm{KB}$ signaling was evaluated using enzyme-linked immunosorbent assay (ELISA), Western blotting, and immunohistochemistry. Results: 6-gingerol could significantly reduce the weight loss caused by DSS in mice models $(\mathrm{P}<0.05)$, which is similar to the therapeutic drug, mesalazine. Immunohistochemistry showed that 6-gingerol can repair the damaged glandular structure gradually caused by DSS, significantly decrease the IL-17 level, and increase IL-10 level in bowel tissue. ELISA revealed that 6-gingerol could significantly decrease the IL17 level and increase IL-10 level in both serum and bowel tissue, and the differences were all statistically significant $(\mathrm{P}<0.05)$. In addition, 6-gingerol could suppress the phosphorylation level of I $\mathrm{B} \alpha$ and $\mathrm{p} 65$, which was up-regulated by DSS. Further analysis with immunohistochemistry indicated p-p65 staining was mainly in the nucleus with some in the cytoplasm after DSS treatment, and the treatment with 6-gingerol could significantly weaken the density of p-p65 both in the cytoplasm and nucleus.

Conclusions: Our study suggests that 6-gingerol may alleviate inflammatory injury in UC mice by regulating $\mathrm{NF}-\kappa \mathrm{B}$ signaling pathway.

Keywords: Ulcerative colitis (UC); inflammatory injury; IL-17; IL-10; 6-gingerol; NF-кB

Submitted Mar 04, 2020. Accepted for publication Jun 23, 2020.

doi: 10.21037/apm-20-903

View this article at: http://dx.doi.org/10.21037/apm-20-903

\section{Introduction}

Ulcerative colitis (UC) is a chronic non-specific inflammatory disease of the intestine, which is characterized by recurrent diarrhea, mucopurulent bloody stools, internal urgency, and abdominal pain $(1,2)$. In addition to intestinal symptoms, there are also a variety of extraintestinal symptoms. The exact etiology and pathogenesis of UC are still unknown. Currently, UC is considered to be related to genetic, environmental, immune, infectious, and other factors, with immune-inflammation injury being the most recognized mechanism (3).

Clinically, aminosalicylic acid, glucocorticoid, immunosuppressant, and biological agents are mainly used in the treatment of UC. The long-term use of these drugs will cause greater side effects, and especially 
Table 1 Treatment of mice in each group

\begin{tabular}{lcl}
\hline Group & Number & Treatment \\
\hline A & 6 & Free to drink distilled water for 2 weeks \\
B & 6 & Free to drink distilled water for 2 weeks, and 6-gingerol was given once a day at a dose of $250 \mathrm{mg} / \mathrm{kg}$ \\
C & 6 & Free to drink distilled water for the first week and $4 \%$ DSS water for the next week \\
D & 6 & $\begin{array}{l}\text { Free to drink distilled water for the first week and } 4 \% \text { DSS water for the next week, and given 6-gingerol once a day for } \\
2 \text { weeks at a low dose of } 100 \mathrm{mg} / \mathrm{kg}\end{array}$ \\
E & 6 & $\begin{array}{l}\text { Free to drink distilled water for the first week and } 4 \% \text { DSS water for the next week, and given 6-gingerol once a day for } \\
2 \text { weeks at a high dose of } 250 \mathrm{mg} / \mathrm{kg}\end{array}$ \\
F & 6 & $\begin{array}{l}\text { Free to drink distilled water for the first week and } 4 \% \text { DSS water for the next week, and given mesalazine once a day } \\
\text { for } 2 \text { weeks at a dose of } 20 \mathrm{mg} / \mathrm{kg}\end{array}$ \\
\hline
\end{tabular}

Note: (I) 6-gingerol was purchased from Herbpurify (Chengdu, China; purity 97.8\%), and was administered to mice by gavage. (II) DSS was purchased from Yuanye (Shanghai, China) at a concentration of $4 \%$ (4 g DSS dissolved in $100 \mathrm{~mL}$ distilled water). (III) Mesalazine was administered to mice by gavage. DSS, dextran sulfate sodium.

impact reproductive function. Recent studies have shown that ginger has a wide range of pharmacological effects, including those of anti-inflammation, antioxidation, immune enhancement, etc. Gingerol is the main spicy substance extracted from ginger, comprising more than 10 components (4), of which 6-gingerol has the highest ingredient conten and the strongest biological activity. A previous study (5) found that 6-gingerol can inhibit the primary and secondary inflammatory reactions in adjuvant arthritis rats by inhibiting the cyclooxygenase and lipoxygenase in the metabolism of arachidonic acid, and reducing the biosynthesis of inflammatory mediators, prostaglandin and leukotriene. Ajayi et al. $(6,7)$ found that 6-gingerol could alleviate intestinal inflammatory damage and improve weight loss in mice with colitis.

Regulatory T cells (Tregs) and Thl7 cells are the 2 main $\mathrm{T}$ cell types involved in immune-inflammation response. Thl7 cells mainly secrete IL-17 to mediate inflammatory response (8), while Treg cells mainly secrete inhibitory cytokine, IL-10 (6), to maintain immune tolerance. Treg cells and Th17 cells restrict each other to maintain immune balance. It was reported (9-11) that Thl7 cells in intestinal mucosa and peripheral blood of UC patients increased significantly, while Treg cells in intestinal mucosa increased and Treg cells in peripheral blood decreased, suggesting that the imbalance of Treg/Thl7 cells may be involved in the development of UC. In a previous study, we regulated the cell balance of Th17/Treg and relieved the inflammatory response systematically and locally (not published), thus identifying 6-gingerol as an effective treatment for dextran sulfate sodium (DSS)-induced UC in mice; however, the underlying mechanism of this effect remains elusive.

In this study, we used a DSS-induced colitis model in mice to observe the interventional effect of 6-gingerol on colitis in mice and explore its anti-inflammatory mechanism. We hope this will provide a theoretical basis for the treatment of UC with 6-gingerol.

We present the following article in accordance with the ARRIVE reporting checklist (available at http://dx.doi. org/10.21037/apm-20-903).

\section{Methods}

Animal experiments were approved by The Third People's Hospital of Wuxi Medical Ethics Committee, and is compliance with the institutional guidelines for the care and use of animals.

\section{Animal experiment}

Male BALB/c mice (20-22 g) at 6-8 weeks of age were purchased from Sino-British SIPPR/BK Lab., Animal Co., Ltd. (Shanghai, China) and housed in the animal facility in accordance with the approved protocol. As shown in Table 1, mice were Randomly divided into 6 groups. All the mice were monitored for weight loss, and sacrificed after 2 weeks.

\section{Immunobistochemistry}

All samples were fixed in 4\% formaldehyde solution and embedded in paraffin. The paraffin-embedded sections were dewaxed in xylene, rehydrated in graded alcohols, and 


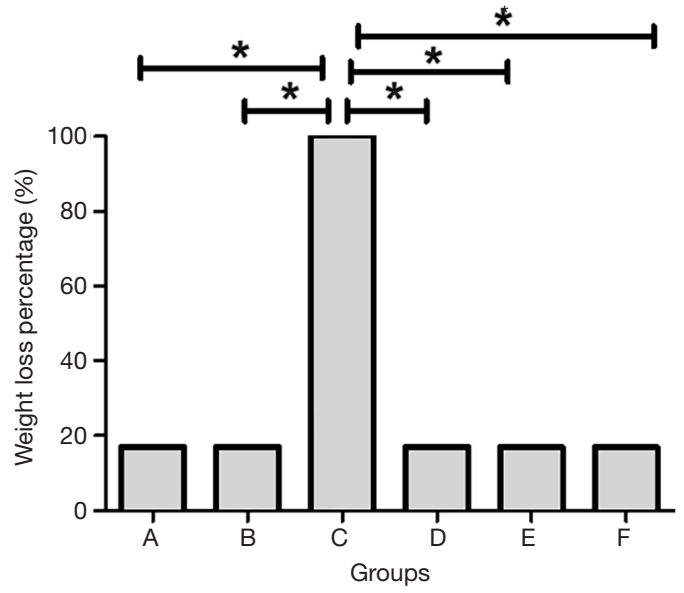

Figure 1 Weight loss in each group. *, $\mathrm{P}<0.05$.

then the sections were pretreated for heat-mediated antigen retrieval with sodium citrate buffer $(10 \mathrm{mM}, \mathrm{pH}$ 6.0) via the microwave method for $20 \mathrm{~min}$. Endogenous peroxidase activity was suppressed by exposure to $3 \%$ hydrogen peroxide for $10 \mathrm{~min}$. Slides were then blocked with $5 \%$ bovine serum albumin (BSA), incubated with diluted primary antibody Phospho-NF- $\mathrm{B}$ p65 (p-p65) (1:1,400, CST, USA) or

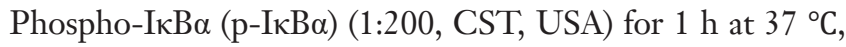
and then incubated with secondary antibody at a dilution of $1: 2,000$ (CST, USA) for $20 \mathrm{~min}$ at $37^{\circ} \mathrm{C}$. Slides were visualized with diaminobenzidine (DAB) and counterstained with hematoxylin for microscopic examination.

\section{Enzyme-linked immunosorbent assay (ELISA)}

Commercial ELISA kit was used to detect the levels of IL-17 and IL-10 in serum and bowel tissues in mice according to the manufacturer's instructions. Briefly, a serially diluted standard sample and serum and bowel tissue samples were added in wells in duplicate $(100 \mu \mathrm{L} /$ well $)$, and incubated for $1 \mathrm{~h}$ at room temperature. Plates were then washed 5 times with washing buffer, and $100 \mu \mathrm{L}$ of biotinylated anti-mice secondary antibody at $1.0 \mu \mathrm{g} / \mathrm{mL}$ was incubated on the plate for $1 \mathrm{~h}$ at room temperature. Plates were washed 5 times with washing buffer and incubated with $100 \mu \mathrm{L}$ of a streptavidin horseradish peroxidase construct at $1.0 \mu \mathrm{g} / \mathrm{mL}$. Plates were washed 5 times with washing buffer and developed for $15 \mathrm{~min}$ in $100 \mu \mathrm{L}$ of a 3,3'5,5'-tetramethylbenzidine substrate solution. The reaction was stopped with the addition of $25 \mu \mathrm{L}$ of 2n H2so4. OD450 values were obtained to develop the standard curve, and the concentration of IL-17 and IL-10 was calculated.

\section{Western blotting}

The proteins were extracted from bowel tissues according to the manufacturer's instructions. The concentration of proteins was determined by bicinchoninic acid (BCA). Then, approximately $25 \mu \mathrm{g}$ of protein was denatured for $10 \mathrm{~min}$ at $95{ }^{\circ} \mathrm{C}$, subjected to $10 \%$ denatured Sodium dodecyl sulfate-polyacrylamide gel electrophoresis (SDS-PAGE), and blotted onto polyvinylidene fluoride (PVDF membrane) $(100 \mathrm{~V}, 60 \mathrm{~min})$. The membranes were blocked with $5 \%$ non-fat milk for $1 \mathrm{~h}$ at room temperature, incubated with p65 and p-p65 (CST, USA) at a dilution of 1:500, and incubated with I $\kappa \mathrm{B} \alpha$ and $\mathrm{p}-\mathrm{I} \kappa \mathrm{B} \alpha$ (CST, USA) at a dilution of 1:500 at $4{ }^{\circ} \mathrm{C}$ overnight. Then, the membranes were reacted with horseradish peroxidase-conjugated secondary antibody IgG (Jackson, MS, USA) at a dilution of $1: 5,000$ at $37^{\circ} \mathrm{C}$ for $1 \mathrm{~h}$. After the final wash, the membranes were developed using an enhanced chemiluminescence detection kit.

\section{Statistical analysis}

All of the data were analyzed using SPSS 19.0 software. Quantitative variables were expressed as mean \pm SD and compared with analysis of variance (ANOVA) among groups, while the differences between 2 groups were analyzed by q test. Categorical variables were expressed as number (\%) and compared by $\chi^{2}$ test. $\mathrm{P}<0.05$ was considered to indicate statistical significance.

\section{Results}

\section{Weight loss of mice}

As shown in Figure 1, there was 1 mouse with weight loss in each of group A and group B, yielding a weight loss rate of $16.7 \%$. All the mice in group C lost weight, yielding a weight loss rate of $100 \%$. There was 1 mouse with weight loss in each of group D, group E, and group F, indicating that the treatment with 6-gingerol or mesalazine reduced the weight loss rate to $16.7 \%$. The difference was statistically significant $(\mathrm{P}<0.05)$.

\section{Cytokine staining in bowel tissues of each group}

As shown in Figure 2, in group A and group B, there were 

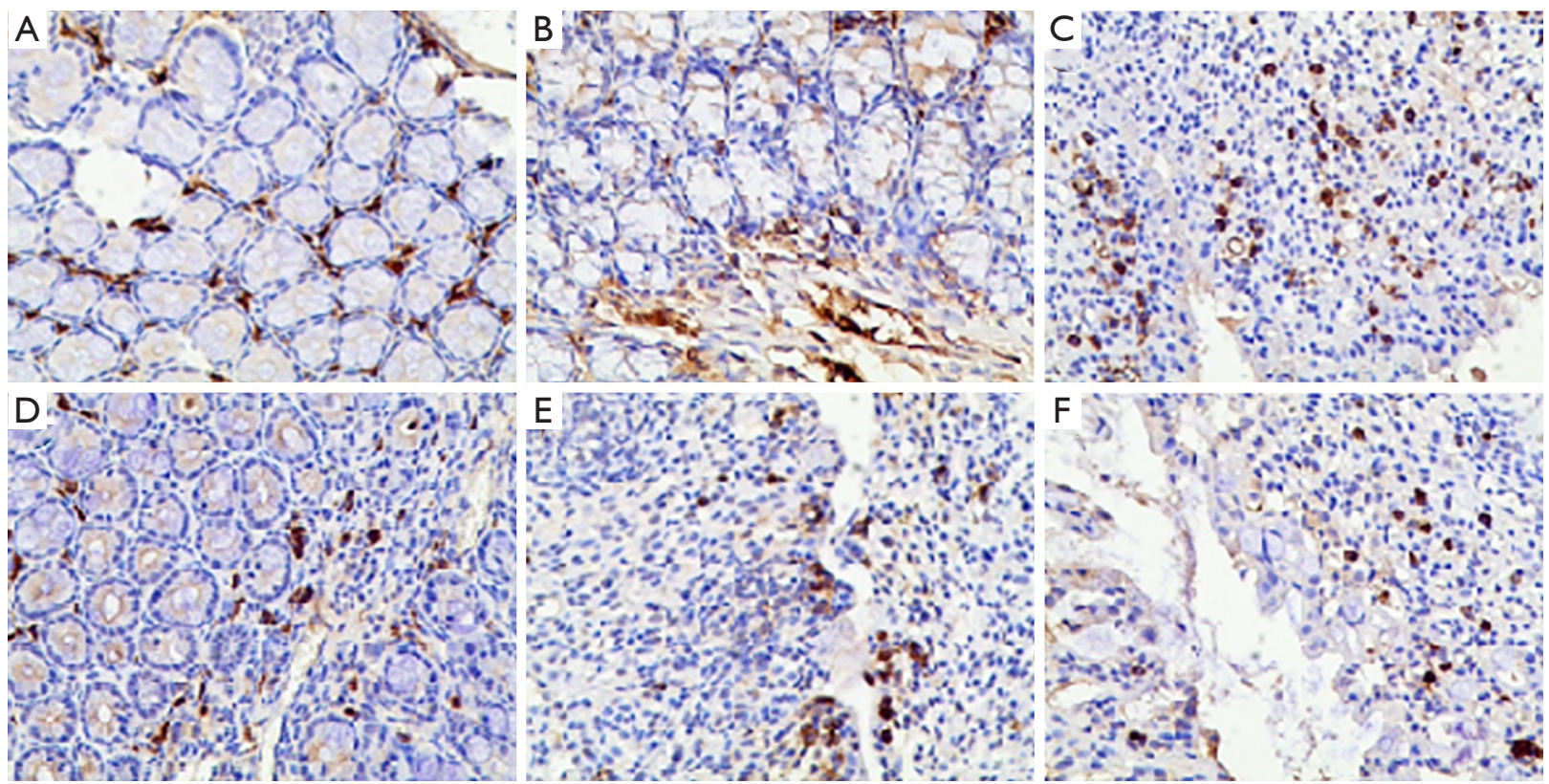

Figure 2 IL-17 staining in the bowel tissues of each group (200×).

normal epithelium, normal gland structure, and complete crypt and goblet cells, with slight IL-17-positive staining (brown staining) in the stroma (Figures $2 A$ and $2 B$ ). Additionally, DSS destroyed crypt and goblet cells on the surface of the mucous membrane, it caused granulation hyperplasia, and prompted a large number of inflammatory cells to infiltrate into the submucosa and muscularis. Immunohistochemical staining showed that the amount of IL-17-positive staining was increased (Figure 2C). 6-gingerol (Figure $2 D, E$ ) and mesalazine (Figure $2 F$ ) treatment gradually repaired the damaged glandular structure, and IL-17-positive staining was decreased compared to DSS treatment.

For IL-10 staining, we found that there was normal epithelium, normal gland structure, and complete crypt and goblet cells, with slight IL-10-positive staining (brown staining) in the stroma in group A and group B (Figure $3 A, B)$. Additionally, DSS destroyed crypt and goblet cells on the surface of the mucous membrane, caused granulation hyperplasia, and prompted a large number of inflammatory cells to infiltrate mucosa. The amount of IL-10-positive staining was decreased (Figure 3C). 6-gingerol (Figure 3D,E) and mesalazine (Figure $3 F$ ) treatment gradually repaired the damaged glandular structure, and IL-10-positive staining was increased compared to DSS treatment.

\section{IL-17 level in serum and bowel tissue of each group}

As shown in Figure 4A,B, DSS increased IL-17 level in serum and bowel tissues (group $C$ ), which was significantly higher than those of group $\mathrm{A}(\mathrm{P}<0.05)$. 6-gingerol alone could significantly decrease IL-17 level in both serum and bowel tissues (group B), which could also suppress IL-17 level induced by DSS at a low dose (group D) or a high dose (group E) in both serum and bowel tissues. Mesalazine could also suppress IL-17 level in both serum and bowel tissues induced by DSS. The differences were all statistically significant $(\mathrm{P}<0.05)$.

\section{IL-10 level in serum and bowel tissue of each group}

As shown in Figure 5A,B, DSS decreased IL-10 level in serum and bowel tissues (group C), which was significantly lower than that of group $\mathrm{A}(\mathrm{P}<0.05)$. 6-gingerol alone could significantly increase IL-10 level in serum, but not in bowel tissue (group B). 6-gingerol could also up-regulate the IL10 level suppressed by DSS at a low dose in serum (group D) and a high dose in both serum and bowel tissues (group E). Mesalazine could also increase IL-10 level in both serum and bowel tissues induced by DSS. The differences were all statistically significant $(\mathrm{P}<0.05)$. 


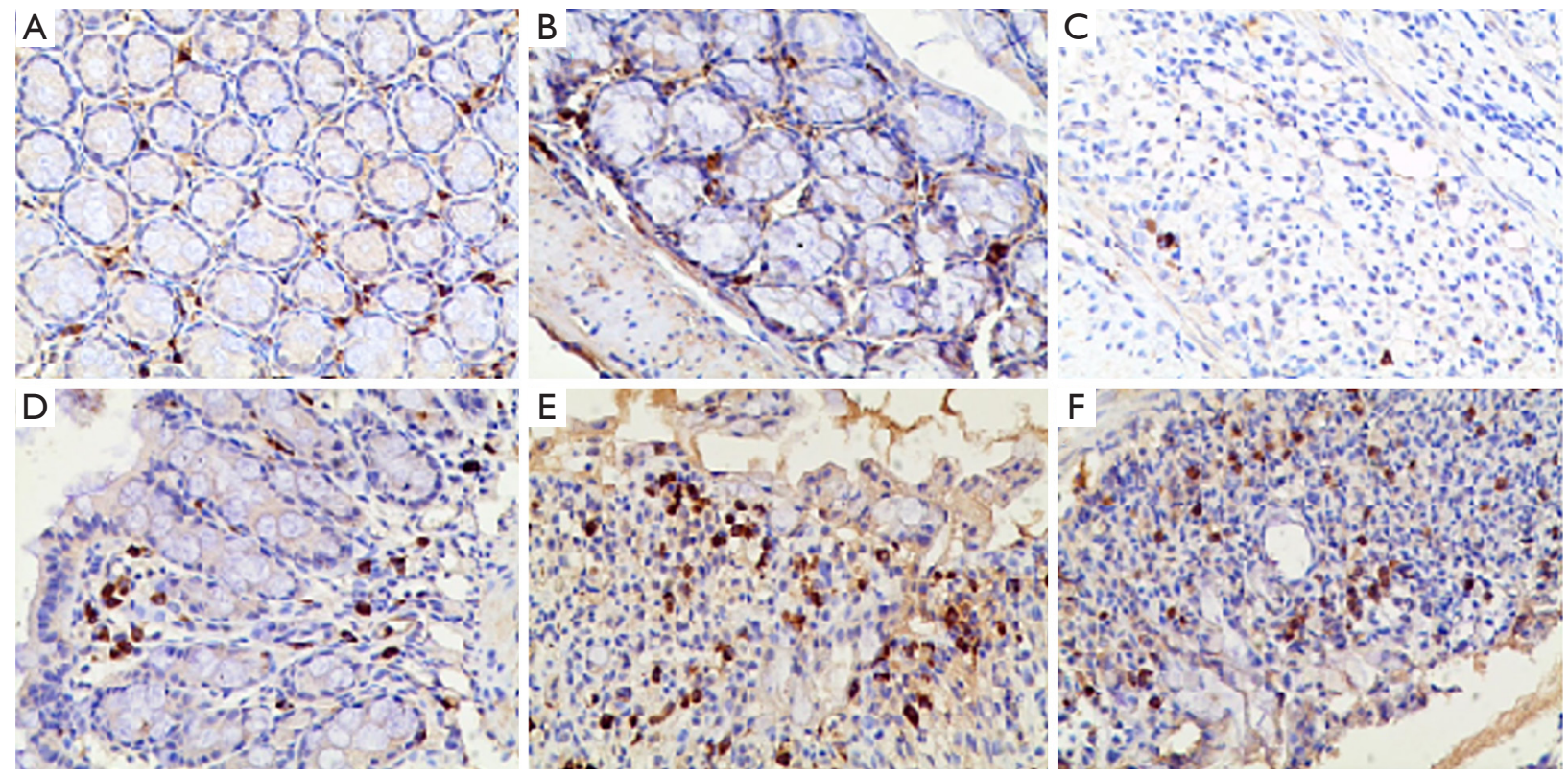

Figure 3 IL-10 staining in the bowel tissues of each group (200x).
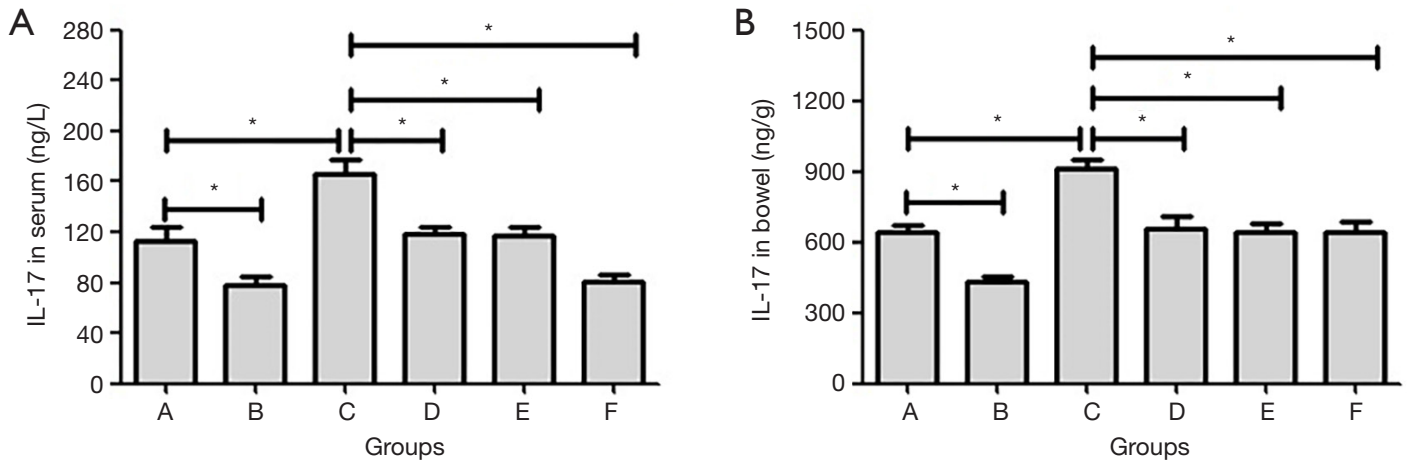

Figure 4 IL-17 level in serum and bowel tissues. *, $\mathrm{P}<0.05$.
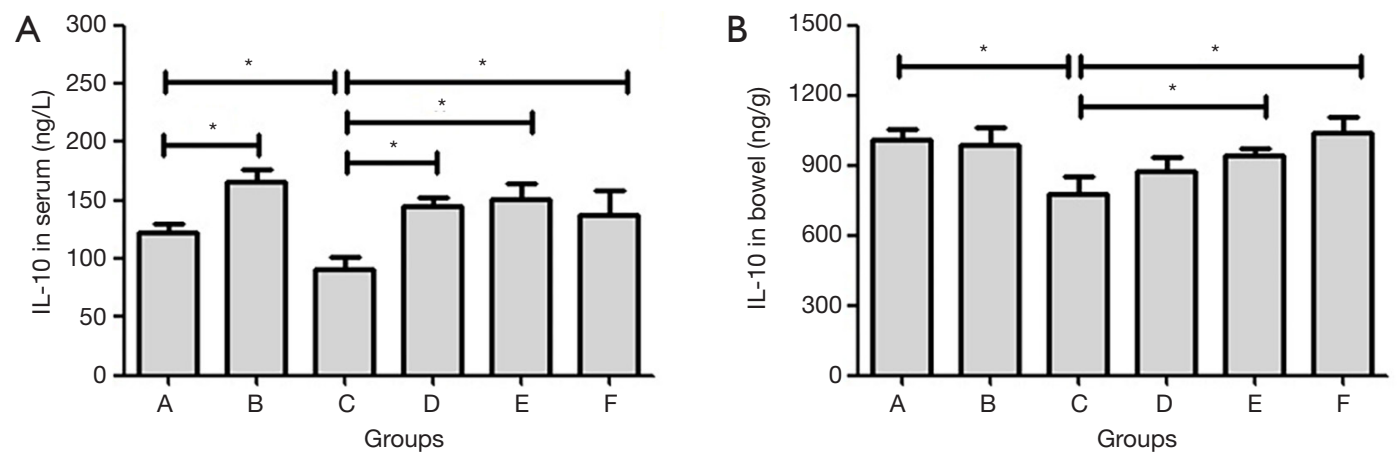

Figure 5 IL-10 level in serum and bowel tissues. *, $\mathrm{P}<0.05$. 


\section{Activation of NF- $\mathrm{\kappa B}$ signaling in each group}

We detected the molecular expression in $\mathrm{NF}-\kappa \mathrm{B}$ signaling, which is shown in Figure 6. DSS increased the phosphorylation level of $\operatorname{I\kappa B} \alpha$ and $\mathrm{p} 65$, which were significantly more expressed than those of group A and group B. Also, the treatment with 6-gingerol and mesalazine could significantly suppress the phosphorylation of I $\mathrm{B} \alpha \alpha$ and p65 induced by DSS.

We also detected the density and location of p-IкB $\alpha$ and p-p65 in the bowel tissue of each group, as shown in Figure 7.

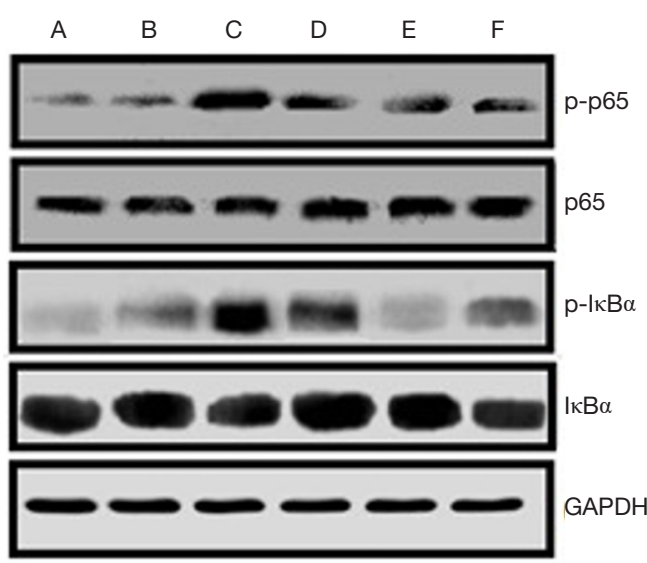

Figure 6 Activation of NF- $\kappa \mathrm{B}$ signaling in each group.
$\mathrm{p}-\mathrm{I} \kappa \mathrm{B} \alpha$ (light staining) was located in the cytoplasm, and no obvious nucleic staining was found (Figure $7 A, B$ ). After DSS treatment, $\mathrm{p}-\mathrm{I} \kappa \mathrm{B} \alpha$ staining was stronger mainly in the cytoplasm with some nuclear staining (Figure $7 C$ ). The treatment with 6-gingerol (Figure $7 D, E$ ) and mesalazine (Figure $7 F$ ) could significantly weaken the density of $\mathrm{p}$-I $\kappa \mathrm{B} \alpha$ both in the cytoplasm and nucleus.

For p-p65, no positive staining was detected both in the cytoplasm and nucleus in group A (Figure $8 A$ ). There was slight staining of p-p65 detected in the cytoplasm but not in the nuclei of group B (Figure 8B). After DSS treatment, p-p65 staining was stronger mainly in the nucleus with some in the cytoplasm (Figure $8 C$ ). The treatment with 6-gingerol (Figure 8D,E) and mesalazine (Figure $8 F$ ) could significantly weaken the density of p-p65 both in the cytoplasm and nucleus.

\section{Discussion}

The current therapeutic drugs for UC include mesalazine, glucocorticoids, and immunosuppressants. Despite their high clinical performance, adverse reactions, especially on fertility, limit their wider application. Consequently, novel and safe drugs for the treatment of UC are urgently needed.

Previous research by our team and others has confirmed the role of 6-gingerol in the treatment of $\mathrm{UC}$ in mice
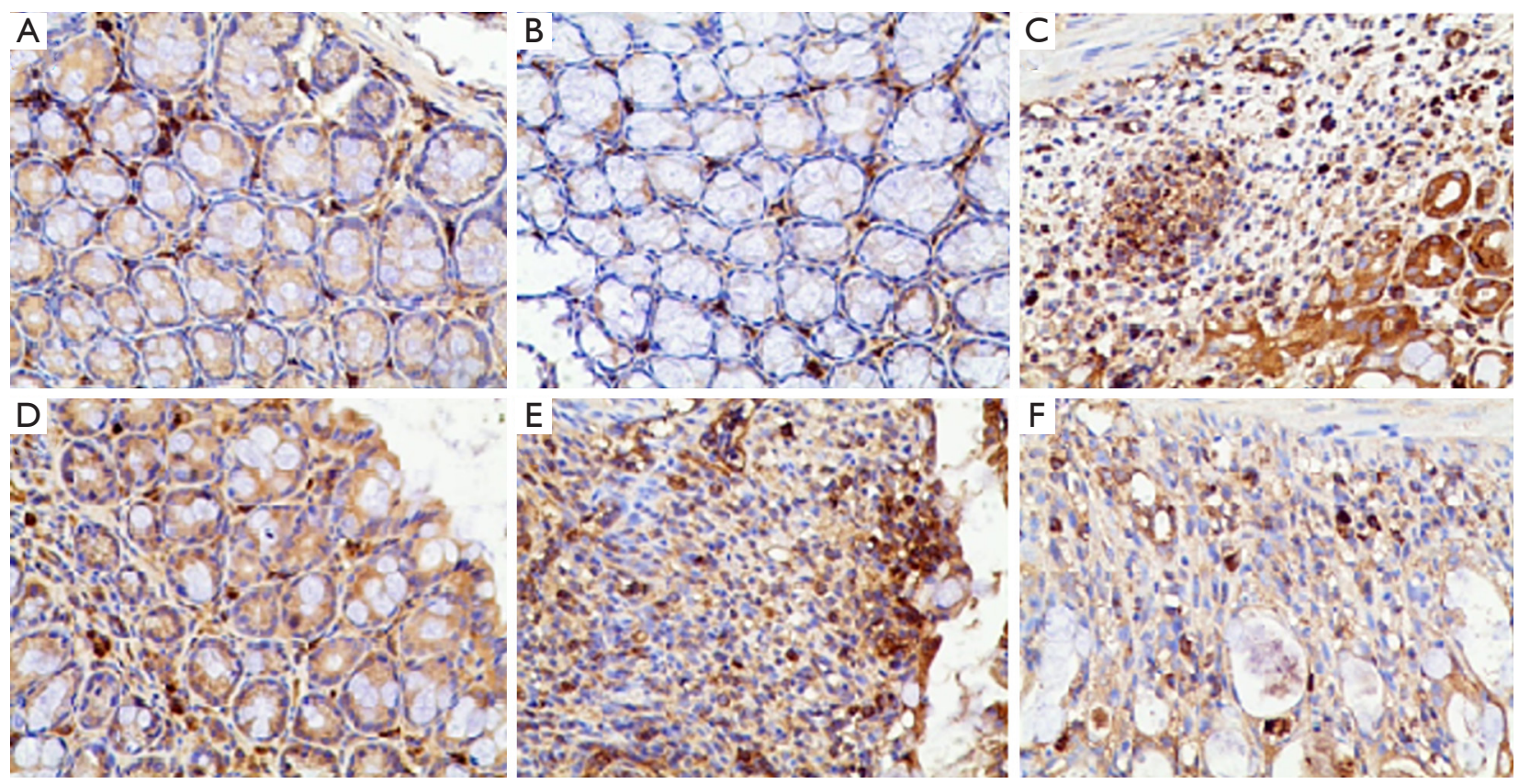

Figure $7 \mathrm{p}-\mathrm{I} \kappa \mathrm{B} \alpha$ staining in the bowel tissues of each group (200x). 

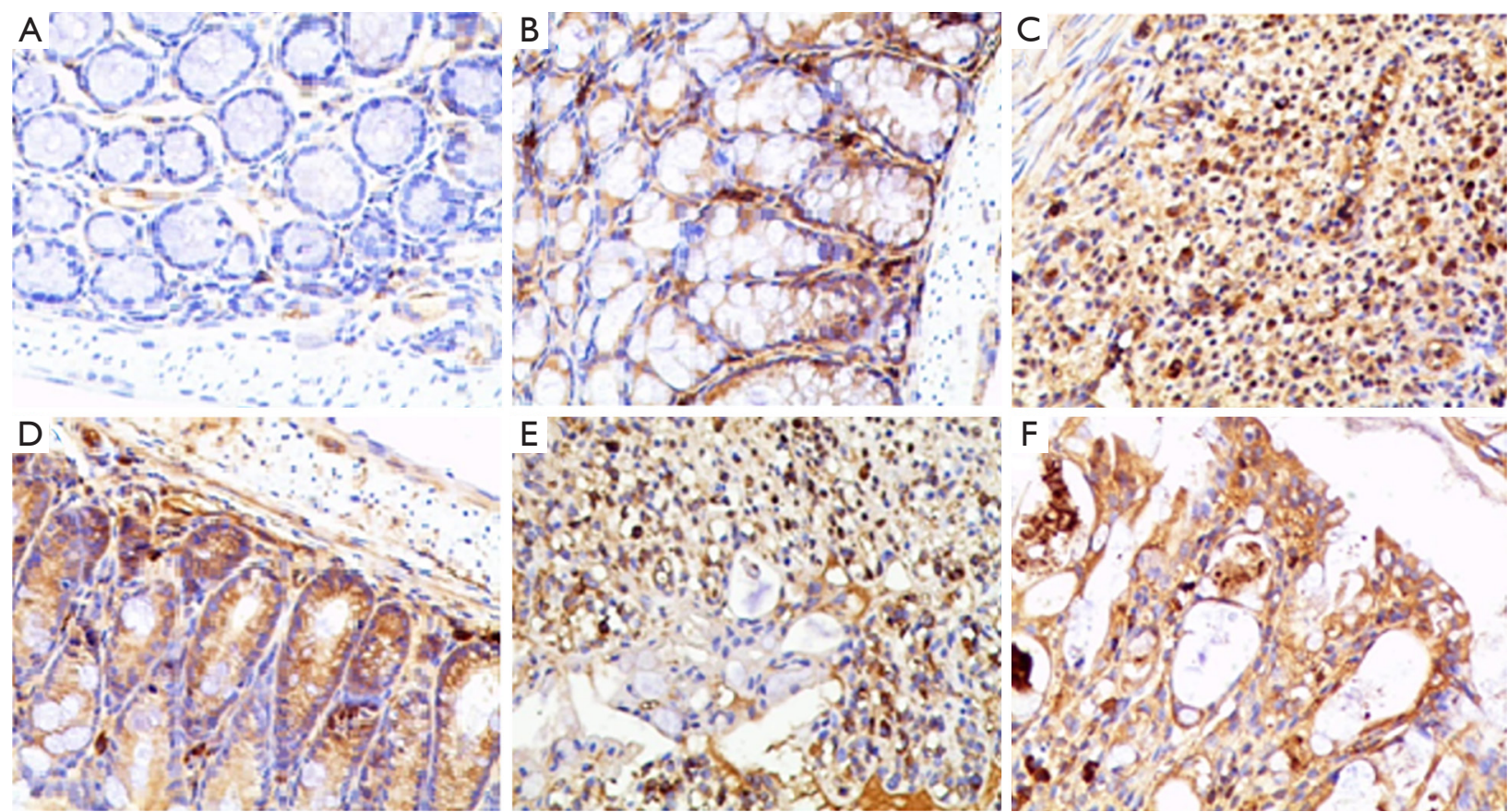

Figure 8 p-p65 staining in the bowel tissues of each group (200×).

models by alleviating intestinal inflammatory injury $(6,7)$, but its underlying mechanism is still unknown. In this study, we aimed to explore the potential anti-inflammatory mechanism of 6-gingerol in DSS-induced colitis mice.

$\mathrm{UC}$ is an immune-mediated intestinal inflammatory disease, which has a variety of pathogeneses (12) mediated by a variety of immunological factors, including Th17 and Treg. Th17/Treg balance is the key factor to maintain intestinal immune homeostasis (13). IL-17 is a pro-inflammatory cytokine, secreted mainly by Th17. Meanwhile, IL-10, which is secreted mainly by Treg, is an anti-inflammatory cytokine. In the current study, we found that 6-gingerol could significantly alleviate the inflammatory injury in bowels of the mice models by decreasing the IL17 level and increasing the IL-10 level in serum and bowel tissue. This supports the notion in which the imbalance of Th17/Treg cells contributes to the progress of UC, which is consistent with a previous report (14).

Nuclear factor- $\kappa \mathrm{B}(\mathrm{NF}-\kappa \mathrm{B})$ is a protein with multidirectional transcription regulation and consists of 5

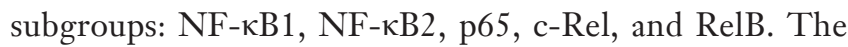
active form is a dimer composed of different subgroups, the most important of which is $\mathrm{p} 50 / \mathrm{p} 65$ heterodimer formed by $\mathrm{p} 50$ and $\mathrm{p} 65$ encoded by the NF- $\mathrm{\kappa B} 1$ gene and NF- $\kappa \mathrm{B} 2$ gene respectively (14). NF- $\kappa \mathrm{B}$ is involved in the pathogenesis of many inflammatory diseases. It is reported that NF- $\mathrm{KB}$ can upregulate the expression of proinflammatory cytokines in intestinal mucosa, aggravate the inflammation of intestinal mucosa, and cause the apoptosis of epithelial cells. In addition, NF- $\mathrm{BB}$ can promote Th17 cell differentiation by regulating the expression of the transcription factor ROR $\gamma \mathrm{T}$ and the inflammatory factors IL-1 $\alpha$, IL-1 $\beta$, and IL-6 (15-17). Therefore, we further examined NF- $\mathrm{KB}$ signaling in each group. We found that DSS increased the phosphorylation levels of IкB $\alpha$ (p-ІкB $\alpha)$ and p65 (p-p65), and that the treatment with 6-gingerol could significantly suppress the level of p-IкB $\alpha$ and p-p65 induced by DSS. This indicates that DSS can activate NF$\kappa \mathrm{B}$ signaling pathway, triggering an inflammatory response, while 6-gingerol can suppress inflammatory injury by inhibiting NF- $\kappa \mathrm{B}$ signaling pathway.

In a resting state, $\mathrm{NF}-\kappa \mathrm{B}$ is bound to its inhibitor $\mathrm{I} \kappa \mathrm{B} \alpha$ as an inactive form in the cytoplasm. When triggered by lipopolysaccharides (LPS) and/or pro-inflammatory factors such as IL- $1 \beta$ and TNF- $\alpha$, the dimer of NF- $\kappa B$ is dissociated from the complex of $\mathrm{I} \kappa \mathrm{B} \alpha / \mathrm{p} 50 / \mathrm{p} 65$. After this, the activated NF- $\kappa \mathrm{B}$ is transferred to the nucleus and binds to the promoter regions of various active genes in the nucleus; this activated NF- $\mathrm{kB}$ can regulate a variety of inflammatory factors. We, then further examined 
the location of $\mathrm{p}-\mathrm{I} \kappa \mathrm{B} \alpha$ and $\mathrm{p}-\mathrm{p} 65$ in bowel tissue using immunohistochemistry. It was found that, after DSS treatment, p-p65 staining was mainly in the nucleus with some in the cytoplasm, and the treatment with 6-gingerol could significantly weaken the density of p-p65 both in the cytoplasm and nucleus, indicating that 6-gingerol can alleviate the inflammatory response by blocking NF- $\kappa \mathrm{B}$ from entering the nucleus.

There were some limitations in this study. Firstly, the small number of animals included might have caused statistical bias. Secondly, the in-depth mechanism behind the above-mentioned observations needs to be further explored, and this will constitute the continued work of our team. In summary, by regulating $\mathrm{NF}-\kappa \mathrm{B}$ signaling pathway, 6-gingerol is effective in alleviating inflammatory injury in DSS-induced UC mice.

\section{Acknowledgments}

Funding: Our research was supported by the Wuxi City Health and Family Planning Commission "Science and Education Strong” Youth Talent Project (QNRC096); The Key Talents Project of "Strengthening Health through Science and Education" of Wuxi Health and Family Planning Commission (ZDRC039); The Top Talents Project of "Six-one Project" for High-level Health Talents in Jiangsu Province (LGY2018016); The Appropriate Technology Promotion Project of Wuxi Health and Family Planning Commission (T201804).

\section{Footnote}

Reporting Checklist: The authors have completed the ARRIVE reporting checklist. Available at http://dx.doi. org/10.21037/apm-20-903

Data Sharing Statement: Available at http://dx.doi. org/10.21037/apm-20-903

Conflicts of Interest: All authors have completed the ICMJE uniform disclosure form (available at http://dx.doi. org/10.21037/apm-20-903). The authors report grants from Wuxi City Health and Family Planning Commission, grants from High-level Health Talents in Jiangsu Province, during the conduct of the study.

Ethical Statement: The authors are accountable for all aspects of the work in ensuring that questions related to the accuracy or integrity of any part of the work are appropriately investigated and resolved. Animal experiments were approved by The Third People's Hospital of Wuxi Medical Ethics Committee, and is compliance with the institutional guidelines for the care and use of animals.

Open Access Statement: This is an Open Access article distributed in accordance with the Creative Commons Attribution-NonCommercial-NoDerivs 4.0 International License (CC BY-NC-ND 4.0), which permits the noncommercial replication and distribution of the article with the strict proviso that no changes or edits are made and the original work is properly cited (including links to both the formal publication through the relevant DOI and the license). See: https://creativecommons.org/licenses/by-nc-nd/4.0/.

\section{References}

1. Farkas ZC, Keshishyan S, Chakinala RC, et al. Tracheobronchitis with stridor in a patient with ulcerative colitis. Ann Transl Med 2018;6:445.

2. Khor B, Gardet A, Xavier RJ. Genetics and pathogenesis of inflammatory bowel disease. Nature 2011;474:307-17.

3. Kornbluth A, Sachar DB; Practice Parameters Committee of the American College of Gastroenterology. Ulcerative colitis practice guidelines in adults: American College Of Gastroenterology, Practice Parameters Committee. Am J Gastroenterol 2010;105:501-23; quiz 524.

4. Mohd Yusof YA. Gingerol and Its Role in Chronic Diseases. Adv Exp Med Biol 2016;929:177-207.

5. Algandaby MM, El-Halawany AM, Abdallah HM, et al. Gingerol protects against experimental liver fibrosis in rats via suppression of pro-inflammatory and profibrogenic mediators. Naunyn Schmiedebergs Arch Pharmacol 2016;389:419-28.

6. Ajayi BO, Adedara IA, Farombi EO. Pharmacological activity of 6-gingerol in dextran sulphate sodiuminduced ulcerative colitis in BALB/c mice. Phytother Res 2015;29:566-72.

7. Ajayi BO, Adedara IA, Farombi EO. Protective mechanisms of 6-gingerol in dextran sulfate sodiuminduced chronic ulcerative colitis in mice. Hum Exp Toxicol 2018;37:1054-68.

8. Shale M, Schiering C, Powrie F. CD4(+) T-cell subsets in intestinal inflammation. Immunol Rev 2013;252:164-82.

9. Liu X, Zhao Z, Li J, et al. Changes and significance of Treg and Th17 cells before and after treatment of ulcerative colitis. World J Chin Dig 2014;(29):4525-9. 
10. Wu T, Xue L, Dai Y, et al. Changes in the proportion of regulatory $\mathrm{T}$ cells and natural killer cells in peripheral blood of patients with ulcerative colitis. Jiangsu Pharmaceutical 2015;(17):2020-22.

11. Wu T, Xue L, Dai Y, et al. Correlation between CD4 + CD25 + Treg cells in peripheral blood and intestinal inflammatory response in patients with active ulcerative colitis. Int J Dig Dis 2015;(04):293-4, 297.

12. Molodecky NA, Soon IS, Rabi DM, et al. Increasing incidence and prevalence of the inflammatory bowel diseases with time, based on systematic review. Gastroenterology 2012;142:46-54.e42; quiz e30.

13. Fonseca-Camarillo G, Yamamoto-Furusho JK. Immunoregulatory Pathways Involved in Inflammatory

Cite this article as: Sheng $\mathrm{Y}, \mathrm{Wu}$ T, Dai $\mathrm{Y}, \mathrm{Xu} \mathrm{L}$, Zhong Y, Xue Y, Tian Y. 6-gingerol alleviates inflammatory injury in DSS-induced ulcerative colitis mice by regulating NF- $\mathrm{KB}$ signaling. Ann Palliat Med 2020;9(4):1944-1952. doi: 10.21037/ apm-20-903
Bowel Disease. Inflamm Bowel Dis 2015;21:2188-93.

14. Ma Y, Zhang J, Shao S, et al. The changes of regulatory $\mathrm{T}$ cell subsets in DSS-induced ulcerative colitis mice. Chin J Gastroenterol Hepatol 2016;25:294-8.

15. Park SH, Cho G, Park SG. NF-кB Activation in T Helper 17 Cell Differentiation. Immune Netw 2014;14:14-20.

16. Bäcker V, Cheung FY, Siveke JT, et al. Knockdown of myeloid cell hypoxia-inducible factor- $1 \alpha$ ameliorates the acute pathology in DSS-induced colitis. PLoS One 2017;12:e0190074.

17. Zhang R, Tian A, Wang J, et al. miR26a modulates Th17/ $T$ reg balance in the EAE model of multiple sclerosis by targeting IL6. Neuromolecular Med 2015;17:24-34. 